\title{
Bile Duct Adenoma
}

National Cancer Institute

\section{Source}

National Cancer Institute. Bile Duct Adenoma. NCI Thesaurus. Code C2942.

A benign, well-demarcated polypoid neoplasm arising from the bile duct epithelium.

According to the growth pattern, it is classified as tubular, papillary, or tubulopapillary.

Adenomas arising from the extrahepatic bile ducts usually produce symptoms related to biliary obstruction. 